\title{
USING THE EARTH'S NATURAL POTENTIAL FOR HEATING A BUILDING
}

\author{
M. Horneț ${ }^{\text {a, }}$ *, I.L. Cîrstolovean a, D.C. Năstac ${ }^{a}$, Ana Diana Ancaș ${ }^{\text {, }}$, M. Profire ${ }^{\text {b }}$ \\ a Transylvania University of Brasov, Romania, Faculty of Civil Engineering, Department of building services, \\ Str.Turnului 5, Brașov 500152, Romania, e-mail: mircea.hornet@unitbv.ro \\ b Technical University "Gheorghe Asachi" Iași, Romania, Faculty of Civil Engineering and building services, Department of \\ building services, B-dul Dimitrie Mangeron 1, Iași 700050, Romania, e-mail: ancasdaria@yahoo.com
}

Received: 20.02.2018 / Accepted: 28.02.2018 / Revised: 22.03.2018 / Available online: 31.05.2018

DOI: 10.2478/jaes-2018-0006

KEY WORDS: energy consumption, renewable energy, TABS system, heat pump, coefficient of performance.

\begin{abstract}
:
It is known the fact that buildings become one of the major energy consumers. In order to ensure thermal comfort in buildings, more and more complex heating, ventilation and air conditioning systems have been used over time, which are currently large primary energy consumers. At the same time, today, the main source of energy production is still the burning of fossil fuels, which is the process leading to significant emissions of greenhouse gases. That is why the current European Union directives enforce both reducing buildings energy consumption with $20 \%$ before 2020 and using an amount of $20 \%$ of renewable energy. One of the heating systems that best respond to the need to reduce the energy consumption of buildings is the low-temperature radiant heating system., This is the reason why the present paper presents a research project that concerns the use of TABS heating/cooling systems that harness the renewable geothermal energy of the ground provided by a ground-air heat pump in Romania. The experimental research building is one of the research laboratories of the Research, Development, Innovation Institut of Transilvania University of BrasovRomania In the first cold season of activity for heating the experimental building (2017-2018), the system provided a thermal enegy of $48 \mathrm{MWh}$, covering $48 \%$ from the amount of the heating load. During the monitored period, the average COP for heating of the heat pump was 4,6 . The research will continue to take place, results regarding the economy for cooling the building in the warm season and for the year's transition periods being expected to follow.
\end{abstract}

\section{INTRODUCTION}

Buildings represent one of the important energy consumers and are responsible for a significant amount of green house gas, which cause climatic changes. Out of the total energy consumption of European Union residential buildings, the largest share of about $69 \%$ is used for heating and cooling spaces, $14 \%$ for hot water preparation , $13 \%$ for lighting and household appliances and 4\% for cooking (Dragomir, 2015).

Providing thermal comfort in buildings imposed over time the use of complex heating, ventilation and conditioning systems which are big primary energy consumers. These have known a rapid spread in the last decades of the past century, when the energy price was very low. Once the energy price went up, this heating/cooling solution became a less rational concept (Morone, 2014).

Currently, the traditional source of obtaining energy still consists in burnig fossile fuel, proces followed by major greenhouse gas emissions, especially carbon dioxide. This and the fact that fossile fuel reserves are limited rise the desire to decrease the quantity of energy produced by burning them. In the same time, because of the continuous development of human society, the wnergy demand at global scale is growing bigger (Luoa et al., 2015).

Beside lowering the energy consumption, an important role in the sustainable development is represented by the use of renewable energy. Intererest, increasing on the global scale, for the use of renewable energy in heating/cooling led to the use of low temperature heat sources, such as: ground, groundwater, water from lakes, etc. The most common extraction method of thermal energy from these sources is the use of heat pumps, whom efficiency grows as the temperature between the energy source and the thermal agent decreases.

At the moment, the heating/cooling systems which repond in the best way to the new conditions for decreasing the energy consumption, for the use of renwable energy and increase of thermal comfort, are the low temperature radiant systems, used

\footnotetext{
* Corresponding author: Mircea Horneț, e-mail: mircea.hornet@unitbv.ro
} 
together with ventilation/conditioning systems which ensure only the minimum needed fresh air flow for physiologic comfort. These systems feature low temperatures for the thermal agent during the heating season, respectively high temperatures for the thermal agent during the cooling season (Babiak et al., 2014). The small temperature difference between the radiant surface and the interior air recommends using these systems in the company of a series of high efficiency equipments, respectively with those which use renewable energy, such as: heat pumps, solar panels, condensing boilers as well as the ones that use the ground water for natural cooling (Bloomquist, 2003).

Among the heating/cooling systems that use low temperature radiant surfaces is also found the thermo-active building systems (TABS).

Although the TABS are the last appeared from the heating/cooling (in the beginning ot the 1990s), they spread rapidly, both in the non-residential and residential building. In the beginning of 2001, in Germany there were approximatively 60 buildings equipped with TABS, with a heating/cooling surface between 250 and 40000 square meters (Meierhans and Olesen, 2001), and in 2003 a third of the new commercial buildings were equipped with these systems. In Switzerland, in 2003, the estimated TABS surface was about 100000 square meters (Koschenz and Lehmann, 2003), reaching 460000 square meters in 2007. During this short amount of time, between 2001 and 2007, the TABS systems succeeded in recovering the gap from radiant panels, the installed surface being smaller with only $27 \%$. Today, the TABS heating/cooling systems are used in almost all of the building categories: residential, office, industrial buildings, sport halls, cultural buildings, etc.

In Romania, the TABS heating/cooling systems are very uncommon in contrast to other ocuntries from the European Union. Therefore, it is important to know: 1) the functional performance of this type of system, for the climatic particularities of Romania; 2) the efficiency of the ensemble formed by a TABS heating/cooling system and the geothermal pump (pumps). These are the reasons why the present collective.

\section{MATERIALS AND METHOD}

\subsection{The experimental building}

The building in which the experimental research presented in this paper was conducted is one of the 12 identical buildings, dedicated to research laboratories, which are part of the Research, Development, Innovation Institut of Transylvania University of Braşov-Romania (Todor et al., 2017). The authors of this article were part of the collective that designed the interior installations from these buildings and those from the entire recalled institute.

The buildings (including the experimental one) were finalised in 2012. It is composed of semi-basement, ground level and first level, the built area being of 1440 square meters. The resistence structure of the building consists of reinforced concrete pillars and longitudinal and transversal frames. The external walls are made of BCA GBC 50 which are $20 \mathrm{~cm}$ thick and plated with anodised aluminum panels, isolated with polystyrene insulation with a thickness of $10 \mathrm{~cm}$. The horizontal elements of the resist structure are made of monolithic reinforced concrete panels of $15 \mathrm{~cm}$ thick. The roof is terraced and has a $40 \mathrm{~cm}$ thick mineral wool insulation. The building is located in an open area. Figure 1 shows an overview of the experimental building in which the main façade can be seen.

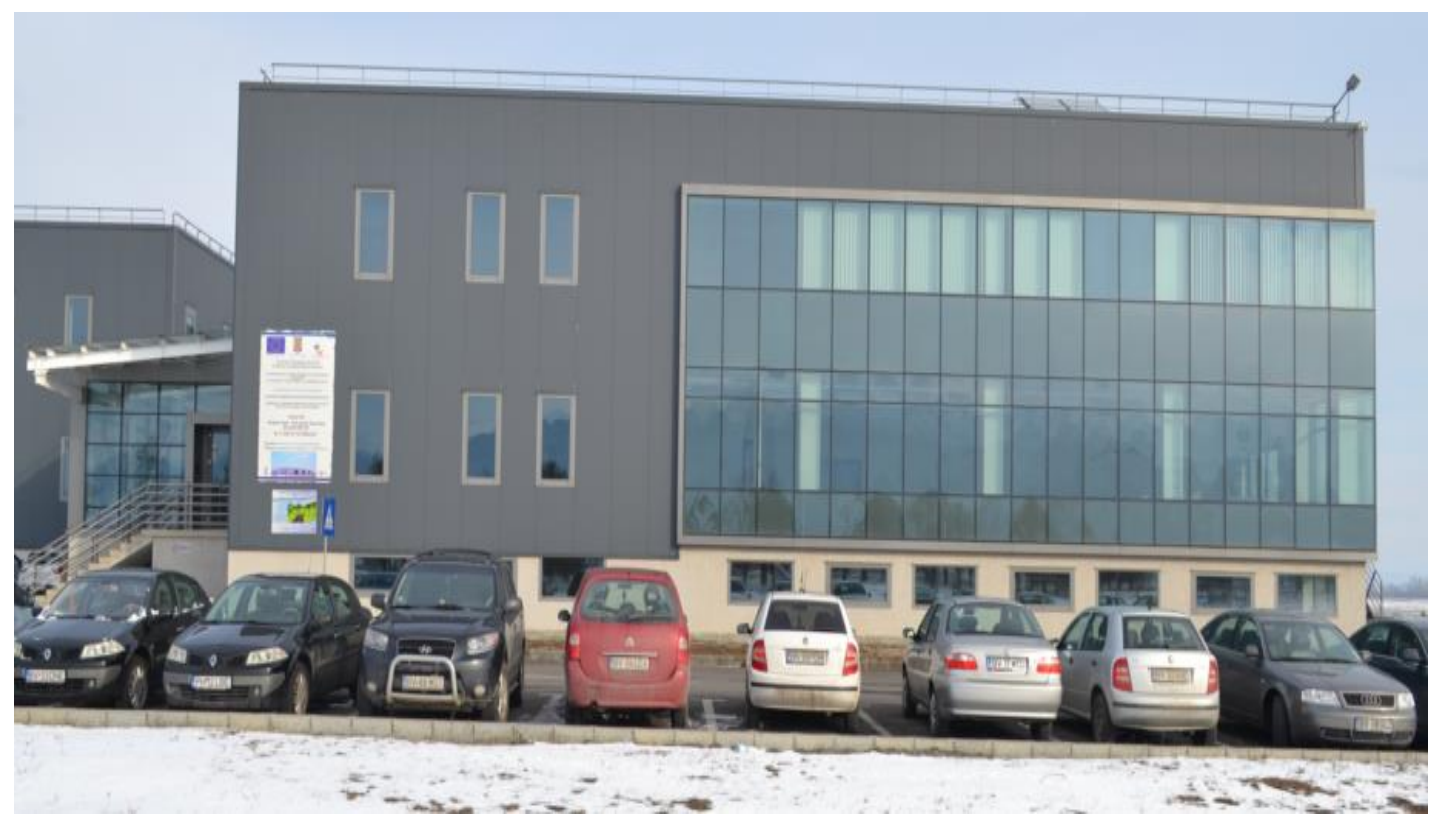

Figure 1. Overview of the main facade of experimental buildings 


\subsection{The design of the building as a low-energy building}

From the very beginning, the buildings were designed as lowenergy buildings, given that in the near future this campus aims to become independent in terms of energy acquirement. To this end, the following measures were adopted:

- Orientation of the main facade of the building to the south.

- The building was designed with two glazed curtain walls. One is situated on the southern façade, with an area of approximately $90 \mathrm{~m}^{2}$ and another on the western façade, with an area of approximately $36 \mathrm{~m}^{2}$.

Obviously, this is an impediment during the warm season due to the increase in solar thermal inputs (in Romania, the solar inputs in the summer through a triple glazed surface are: about $6.5 \mathrm{MJ} / \mathrm{m}^{2}$ - for south orientation and $5.5 \mathrm{MJ} / \mathrm{m}^{2}$ - for west orientation).
- The possibility of uncontrolled opening of the operating windows has been eliminated. Thus, only a small part of them can be opened for a controlled supply of fresh air, given that the buildings are not equipped with centralized ventilation and air conditioning systems.

- Taking into account the building's massive thermal mass and the desire to make the most of the heat from the solar panels mounted on the roof terrace, the TABS heating system was adopted. It was installed in all three concrete floors of the building (terrace, first level floor and the ground level floor).

Figure 2 shows the plan of the TABS heating system mounted in the concrete slab of the ground floor of the building.

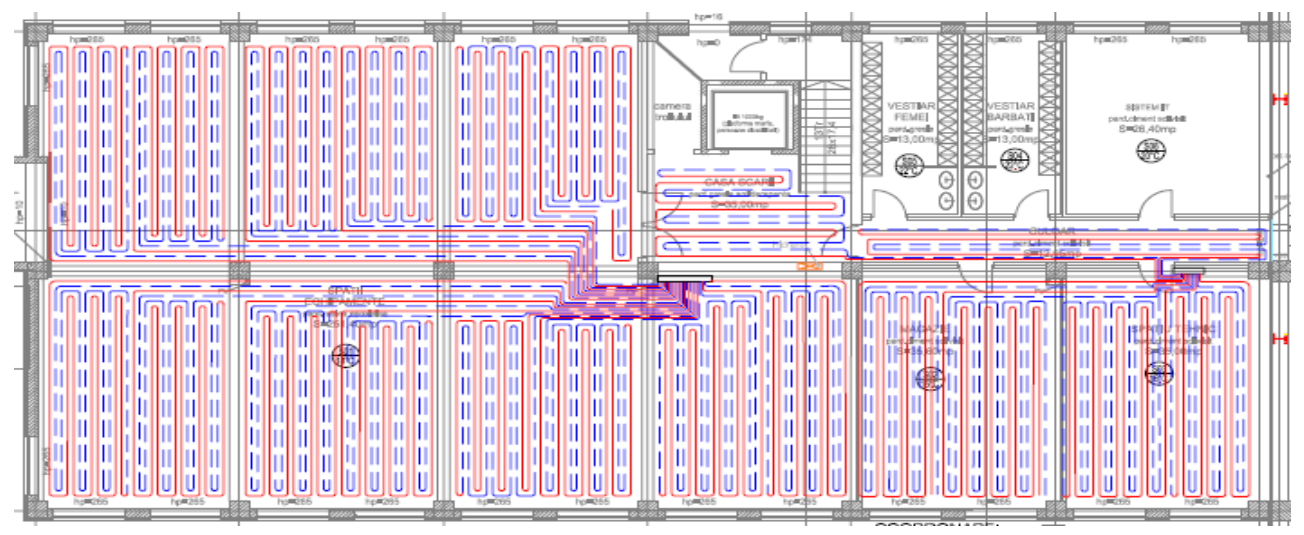

Figure 2. Floor plan of the building's ground floor heating

Until the moment of the design and commissioning of a heat source energy for all the institute buildings, every building is provisionally suplied with heat from a condensing boiler, with natural gas.

In order to carry out the experimental research presented here, only in the experimental building was mounted a ground-water heat pump. This heat pump can function reversibly. Its intended mode of operation is:

- in the cold season, in order to heat the building, the heat pump takes over the heat stored in soil through four boreholes witth depth of 100 meters;

- in the the warm season, for cooling (the thaking over of solar thermal intakes through concrete floors), the heat pump works in passive mode (the water circulating in the TABS systems is cooled from the ground by simply runnig the circuits from the four boreholes).

For this, in installation where mounted:

- one plate heat exchanger

- one buffer tank with a capacity of 3000 liters, to which the solar panels are also connected, for heating in the cold season.

Also, for measuring the thermal energy taken from soil in the cold season, four heat energy meters and four water meters which measures the flow of water circulated in drillings (one for each drilling) were mounted.

In Figure 3 is presented a image of the heat pump to together with the afferent piping system.

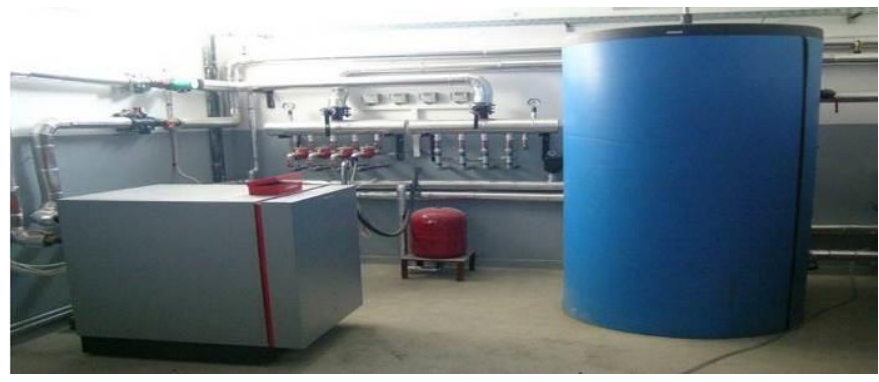

Figure 3. Heat pump mounted

in the experimental building 


\section{RESULTS AND DISCUSSION}

\subsection{Heat pump performance on energy saving}

The performance analysis of the heat pump soil-water in the cold season was done between 15.10.2017 and 15.02.2018, using the measurements from the experimental building. The energy for building heating provided during this period, calculated with the measured data, was $48 \mathrm{MWh}$. The average COP of the heat pump for heating over the mentioned period, calculated with the measured data, was 4.6.

An important parameter that influences the COP of the heat pump is the temperature of the primary heat agent. It is well known that an high temperature of the heat pump on the primary heat pump circuit increases its efficiency (Jingjuan et al., 2014). Analyzing the measured values of primary heating agent (both flow and return), it was observed to decrease its temperature during the monitoring period by about $1.3^{\circ} \mathrm{C}$, as shown in Figure 4.

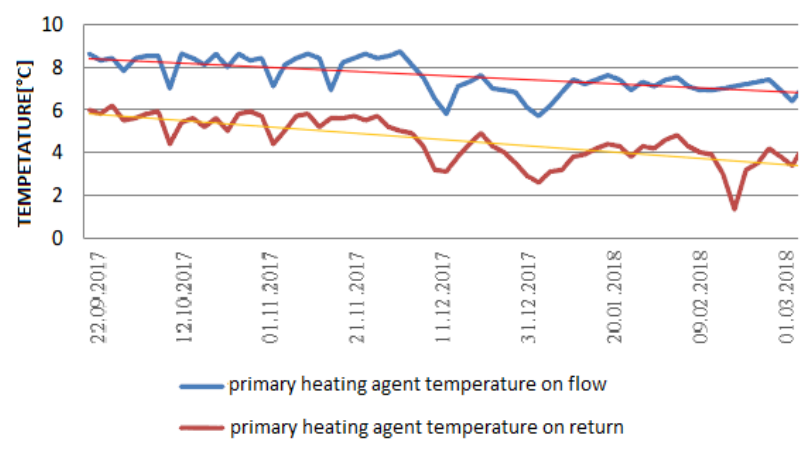

Figure 4. Heat pump primary heating agent temperature between 15.10.2017 and 15.02.2018

As the temperature of the primary heat agent decreases, a decrease in the COP heat pump is recorded. At the beginning of the cold season COP for heating had high values of 4.9, decreasing towards the end of the period at values of 4.4. as can be seen in Figure 5.

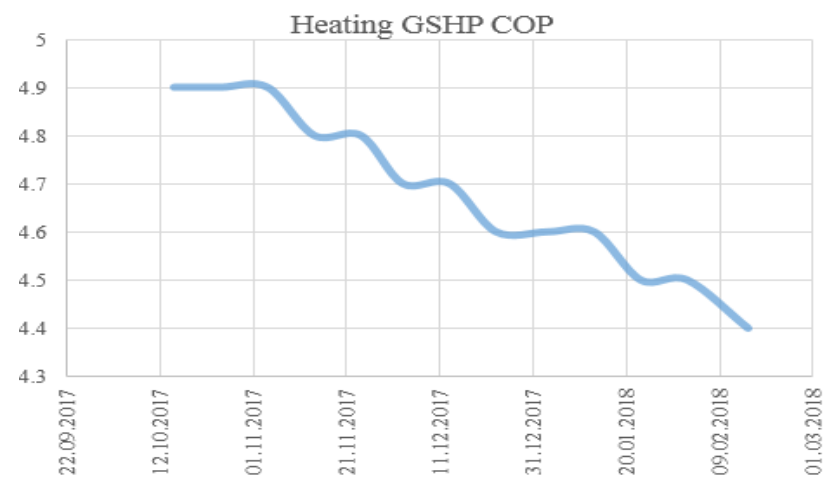

Figure 5. Heat pump COP for heating and d.h.w. between 15.10.2017-15.02.2018

\subsection{Heat pump performance to reduce greenhouse gas emissions}

A generaly recognised solution for the greenhouse gasses emission that are released into the athmosfere reduction in heating/cooling buildings is the replacement of the conventional sollutions of heating/cooling with heat pumps. When calculating greenhouse gas savings by replacing a conventional heating solution with GSHP, we must take into account all emissions from the entire energy cycle (fuel extraction, transport, etc.) and the conversion of hydrocarbs into heat for heating and cooling (Blumsack et al., 2009). For the calculation of the quantity of reduced emissions, using the heat pump over conventional energy systems for heating, the following relationship can be used (Boian I, 2007):

$$
G H G=C_{e} \cdot\left(\frac{I_{f}}{\eta}-\frac{I_{E}}{3,6 \cdot C O P}\right) \cdot 10^{-3} \quad\left[t_{\mathrm{CO}_{2}} / \mathrm{an}\right]
$$

where $I_{f}=$ greenhouse gases intensity emission, specific for the type of fuel used $(50 \mathrm{~kg} \mathrm{CO} 2 / \mathrm{GJ}$ for natural gasses, $73 \mathrm{~kg}$ $\mathrm{CO} 2 / \mathrm{GJ}$ pentru liquid fuel and $98 \mathrm{~kg} \mathrm{CO} 2 / \mathrm{GJ}$ for coal),

$I_{e}=$ the specific emission intensity for the efficiency of the electricity generation process,

$C O P=$ the heat pump performance coefficient,

$C_{e}=$ the energy consumption index for heating,

$H=$ heating boiler efficiency.

Using the greenhouse gas emission values for different types of energy conversion in electricity produced in Romania after Dragomir (Dragomir G., 2015), namely: for coal energy 800$1000 \mathrm{gCO} 2$ / KWh; for electricity from liquid fuel $400 \mathrm{gCO} 2 /$ $\mathrm{KWh}$; for hydroelectric power $0,35-, 30 \mathrm{gCO} 2 / \mathrm{KWh}$; for nuclear power 2.8-28 gCO2 / KWh; for wind power 8-32 gCO2 / KWh.

We also considered the share of different types of electricity, out of the total electricity produced in Romania, shown in Figure 6, below:

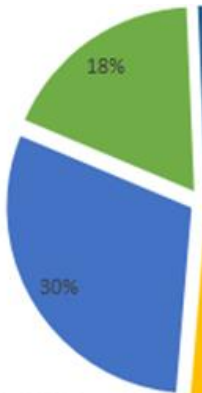

- Photovoltaic $[\%$ in total $]$ a Coal $[\%$ in total $]$

- Hydro Power $[\%$ in total $]$

-Wind Power [\% in total]

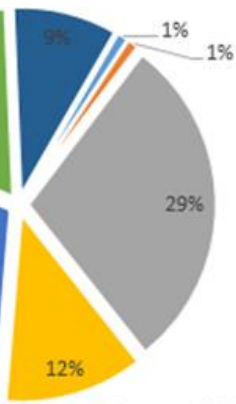

- Biomass $[\%$ in total $]$ = Other Hydrocarbs [\% in total] - Nuclear Power $[\%$ in total]

Figure 6. The share of different types of electricity from the total electricity produced in Romania

Based on the above, we calculated the reduction of greenhouse gas emissions by using a heat pump to heat the experimental building during the monitored period instead of a condensing boiler or a classic boiler. The results are presented in Figure 7. 


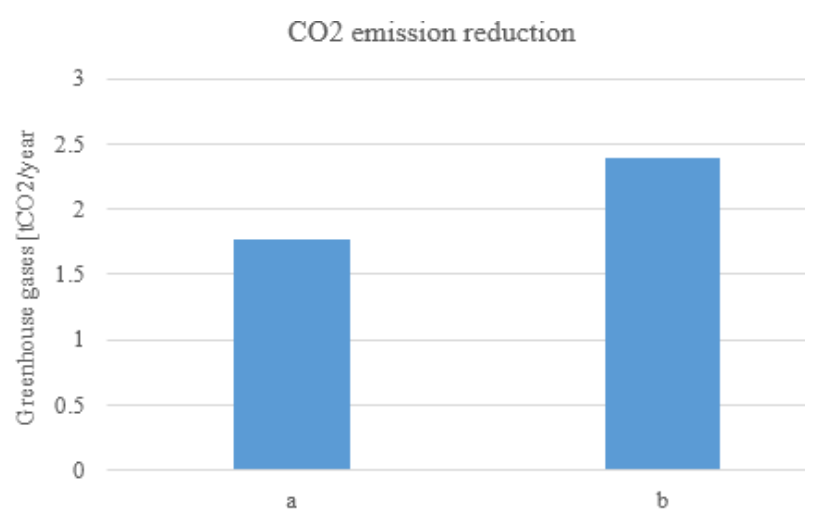

Figure 7. Reducing greenhouse gas emissions by using a heat pump to heat the experimental building ( $\mathrm{a}$ - instead of a condensing boiler, $\mathrm{b}$ - instead of a conventional boiler)

Significant emission reductions are due both to the high COP of the heat pump and to the fact that the heat pump uses electricity with low releases of gas (hydro-electric, nuclear, wind) from the total electricity produced in Romania.

Studies on existing buildings have highlighted the fact that the use of low-temperature radiant systems only for space heating does not bring significantly better results compared to other low-temperature heaters. An important advantage of lowtemperature radiant systems is that they can be used with very low operating costs and space cooling, which increases their performance in reducing the energy consumption of buildings. Therefore, our team has proposed to monitor the operation of the TABS system in the experimental building during the upcoming 2018 season.

\section{CONCLUSIONS}

Lately, low-temperature radiant systems are increasingly being used more often for both heating and cooling, in particular due to the following factors:

- residential and tertiary buildings have a higher degree of thermal insulation;

- long-life and even very long piping materials (eg PE-Xa) have been developed;

- automation and control systems have improved;

- low-temperature renewable energy sources are increasingly being used, and so on.

In Romania, the TABS heating / cooling systems, which operate with heat produced by heat pumps, are less used, compared to many countries in the European Union. One of the reasons is the lack of a specialized technical literature in this area that can provide confidence and encourage the use of these systems. These were the reasons why our team has proposed a research project in this area that is being carried out in situ, in a significant building within a university research institute.

In order to carry out the experimental research presented here, in the experimental building was mounted a ground-water heat pump, which can function reversibly. In order to take heat from the ground during the cold season and to give the heat to the ground during the warm season, the heat pump was connected to four drillings with a depth of $100 \mathrm{~m}$ each. In one of the four drillings, temperature sensors were mounted at a distance of $5 \mathrm{~m}$ to record the variation in the temperature of the earth throughout the year. The sensors were connected to an automatic monitoring system.

Our research project will be carried out over a period of several years and energy savings will be monitored for:

- heating the building during the cold season;

- cooling the building during the warm season;

- heating and cooling the building during the transition periods of the year, spring and autumn respectively.

Also, during this year, in another building identical to the experimental building, we will mount the same type of heat pump, but will be connected to a horizontal serpentine system mounted in the ground at a depth of $1.5 \mathrm{~m}$. Our goal is to perform a comparative study of the energy economy of the two systems for the exploitation of renewable geothermal energy of the earth. Concomitantly, we will also perform a comparative study of the change of soil temperature over a year through the two different systems.

This piece of work presents the first results of the studies and research carried out on the operation of the TABS system only for the heating of the building. They reveal two important things, namely:

1) The fact that the amount of heating energy provided to the building by this system in the three months of operation was of $48 \mathrm{MWh}$. They also highlight:

- decrease of the temperature of primary heat, during the monitored period, by about $1.3^{\circ} \mathrm{C}$;

- Heat pump operation over the monitored period with an average COP of 4.6 and its decrease over the period from 4.9 to 4.4 .

2) Reduction of greenhouse gas emissions by using a heat pump instead of a condensing boiler for heating the experimental building or a classic one.

We hope that once completed, the studies and research under this project will contribute to the development of the literature for these systems in Romania.

\section{REFERENCES}

Boian, I., 2007. Durable development. Building services based on renewable energy, Transilvania University of Brasov Publishing House.

Babiak, J, Olesen, B, Petras, D.,2007. Low temperature heating and high temperature cooling, REHVA Guidebook, Federation of European Heating ahd Air-Conditioning Associations.

Bloomquist, R.G., 2003. Geothermal space heatin, Geothermics, 32, pg. 513-526.

Blumsack, S., Brownson, J., Witme, L., 2009. Efficiency, Economic and Environmental Assessment of Ground-Source Heat Pumps in Central Pennsylvania. System Sciences,. HICSS '09. 42nd Hawaii International Conference. 
Dragomir, G., 2015. Heating/cooling with low temperature radiation systems using geotermal energy, PHd thesis, Transylvania University of Brașov.

Feng, J., Schiavon, S., Bauman, F., 2014. Cooling load differences between radiant and air systems. Energy and Buildings, 2014. P152-159.

Koschenz, M., Lehmann, B., 2000. Thermoaktive Bauteilsysteme TABS, EMPA Energiesysteme /Haustechnik, Duebendorf (Switzerland), 2000.

Luoa, J., Rohna, J., Bayerb, M., Priess, A., Wilkmanna, L., Xiangc, W., 2015. Heating and cooling perform anceanalysis of a ground source heat pump systemin Southern Germany, Geothermics 53 (2015)57-66.

Meierhans, R., Olesen, B. W., 1999. Betonkernaktivierung. Germany: Velta Norderstedt.

Morrone, B., Coppola, G., Raucci, V., 2014. Energy and economic savings using geothermal heat pumps in different Climates, Energy Conversion and Management, Volume 88, D.

Todor, R.,D., Horneț, M., Iordan, N., 2017. Implementing the Life Cycle Cost Analysis in a Building Design, Advanced Engineering Forum; Zurich Vol. 21, pp. 514-519, ISBN 978-30357-1098-4, ISSN 22349898. 